\title{
Responses of Radiation-Hardened Power MOSFETs to Neutrons
}

\author{
James E. Gillberg, Member, IEEE; Donald I. Burton, Member, IEEE; Jeffrey L. Titus, Senior Member, IEEE, \\ C. Frank Wheatley, Life Fellow, IEEE, and Noel Hubbard
}

\begin{abstract}
The test results of recent neutron irradiations performed on a variety of radiation-hardened power MOSFETs manufactured by Fairchild Semiconductor are reported here. Twelve device types from four different families with rated drain breakdown voltages from 30 to 500 volts of which most are nchannels and the others are p-channels, were characterized.
\end{abstract}

\section{INTRODUCTION}

$\mathrm{M}$ ANY military and space systems are designed to operate in various radiation type environments. Potential radiation sources are neutrons and protons. Both of these radiation sources produce ionization and displacement damage. If the system and its individual components are not hardened to these radiation types and others, it could fail to operate properly or even cause catastrophic system failure.

Displacement damage is usually a low concern especially on components that are fabricated with highly doped, shallow junctions, which are used in most of today's complex integrated circuits. However, components that are widely used in almost every system are power MOSFETs. These devices incorporate a deep, lightly doped, epitaxial layer, which makes them more susceptible to displacement damage. Displacement damage can cause significant changes in a device's electrical performance such as increasing its onresistance and breakdown characteristics or by changing its threshold voltage.

Many of the power MOSFET technologies that have been developed over the past ten years and currently being manufactured today have not been characterized to displacement damage effects. Therefore, a series of tests were designed to characterize displacement damage effects of several power MOSFET devices using different radiationhardened families manufactured by Fairchild (formally Intersil). The first series of power MOSFETs exposed to neutrons at the Pennsylvania State University Breazeale TRIGA Mark III nuclear reactor are reported here. Using these test data, a preliminary database of displacement damage effects on power MOSFETs will be available to system designers. Data are provided in graphical format. Displayed points represent the average of the four samples of each device type exposed at the given neutron fluence.

Manuscript received July 17, 2001. This work co-sponsored by Fairchild Semiconductor and Defense Threat Reduction Agency (DTRA).

J. E. Gillberg is with the Fairchild Semiconductor, Somerville, NJ 08876 USA (telephone: 908-685-6236: e-mail: jim.gillberg@fairchildsemi.com)

D. I. Burton is with the Fairchild Semiconductor, 125 Crestwood Road, Mountaintop, PA 18707 USA

J. L. Titus is with NAVSEA Crane, 300 Highway 351, Crane, IN 47522 5001 USA (telephone: 812-854-1617, e-mail: jtitus@atd.crane.navy.mil).

C. F. Wheatley is a private consultant, 181 Middle Road, Drums, PA 18222 USA (telephone: 570-788-2319).

N. Hubbard is with NAVSEA Crane, 300 Highway 351, Crane IN 47522

U.S. Government work not protected by U.S. copyright

\section{TEST SETUP}

One hundred ninety-two devices representing twelve different device types (16 samples for each device type) were provided by Fairchild in TO-39 type packages. All devices were electrically characterized prior to any neutron exposure by Fairchild. Four samples of each device type were provided to NAVSEA Crane as controls. The controls were used to correlate Fairchild test data and NAVSEA Crane test data. That correlation is not reported here. The other 12 samples of each device type were segmented into three groups of four, which were then placed into anti-static bags. These bags were then sent to Pennsylvania State University for neutron exposure.

Neutron exposures were performed using a "bag-type" test. Each bag was exposed to a specified level of neutrons, which was related to that device's rated drain breakdown voltage. Throughout this paper, neutron fluence is expressed in units of neutrons per square centimeter and is provided as a $1-\mathrm{MeV}$ equivalent for silicon as determined by the dosimetry. Table 1 provides the device type, rated drain-to-source breakdown voltage ( $\left.\mathrm{BV} \mathrm{DSS}_{\mathrm{DS}}\right)$, channel type, and exposure levels.

TABLE 1: DESCRIPTION OF TESTED SAMPLES

\begin{tabular}{|c|c|c|c|c|c|}
\hline $\begin{array}{c}\text { Device } \\
\text { Type }\end{array}$ & $\begin{array}{c}\text { Rated } \\
\text { BV }\end{array}$ DSS & $\begin{array}{c}\text { Channel } \\
\text { Type }\end{array}$ & $\begin{array}{c}\text { Neutron } \\
\text { (Bag 1) }\end{array}$ & $\begin{array}{c}\text { Neutron } \\
\text { (Bag 2) }\end{array}$ & $\begin{array}{c}\text { Neutron } \\
\text { (Bag 3) }\end{array}$ \\
\hline FSGL033 & $30 \mathrm{~V}$ & $\mathrm{~N}$ & $1.1 \times 10^{14}$ & $9.9 \times 10^{14}$ & $2.8 \times 10^{15}$ \\
\hline FSGL035 & $60 \mathrm{~V}$ & $\mathrm{~N}$ & $1.1 \times 10^{14}$ & $9.9 \times 10^{14}$ & $2.8 \times 10^{15}$ \\
\hline & & & & & \\
\hline FSPL033* & $30 \mathrm{~V}$ & $\mathrm{~N}$ & $1.1 \times 10^{14}$ & $9.9 \times 10^{14}$ & $2.8 \times 10^{15}$ \\
\hline & & & & & \\
\hline FSL13A0 & $100 \mathrm{~V}$ & $\mathrm{~N}$ & $1.0 \times 10^{13}$ & $1.0 \times 10^{14}$ & $1.0 \times 10^{15}$ \\
\hline FSL9130 & $100 \mathrm{~V}$ & $\mathrm{P}$ & $1.0 \times 10^{13}$ & $1.0 \times 10^{14}$ & $1.0 \times 10^{15}$ \\
\hline FSL923A0 & $200 \mathrm{~V}$ & $\mathrm{P}$ & $1.0 \times 10^{13}$ & $1.0 \times 10^{14}$ & $1.0 \times 10^{15}$ \\
\hline $2 \mathrm{~N} 7397$ & $250 \mathrm{~V}$ & $\mathrm{~N}$ & $1.0 \times 10^{13}$ & $1.0 \times 10^{14}$ & $1.0 \times 10^{15}$ \\
\hline FSL33A0 & $400 \mathrm{~V}$ & $\mathrm{~N}$ & $1.1 \times 10^{12}$ & $1.1 \times 10^{13}$ & $3.3 \times 10^{13}$ \\
\hline FSL430 & $500 \mathrm{~V}$ & $\mathrm{~N}$ & $1.1 \times 10^{12}$ & $1.1 \times 10^{13}$ & $3.3 \times 10^{13}$ \\
\hline & & & & & \\
\hline FRL130 & $100 \mathrm{~V}$ & $\mathrm{~N}$ & $1.0 \times 10^{13}$ & $1.0 \times 10^{14}$ & $1.0 \times 10^{15}$ \\
\hline FRL9130 & $100 \mathrm{~V}$ & $\mathrm{P}$ & $1.0 \times 10^{13}$ & $1.0 \times 10^{14}$ & $1.0 \times 10^{15}$ \\
\hline FRL234 & $250 \mathrm{~V}$ & $\mathrm{~N}$ & $1.0 \times 10^{13}$ & $1.0 \times 10^{14}$ & $1.0 \times 10^{15}$ \\
\hline
\end{tabular}

Irradiated devices were sent to NAVSEA Crane for electrical characterization, using a Tektronix-370 curve tracer. Measurements consisted of the following DC electrical tests:

a.) reverse gate-to-source leakage current ( $\left.\mathrm{I}_{\mathrm{GSS}}\right)$,

b.) drain-to-source leakage current ( $\mathrm{I}_{\mathrm{DSS}}$ ),

c.) drain-to-source breakdown voltage ( $B_{\text {VDSs }}$ ),

d.) gate threshold voltage $\left(\mathrm{V}_{\mathrm{TH}}\right)$, and

e.) drain-to-source on-state voltage $\left(\mathrm{V}_{\mathrm{DSON}}\right)$ 
Neutrons do not exhibit electrical charge (neutral) and their mass is slightly larger than protons. Therefore, neutrons penetrate deeply into most materials because they do not interact electrically. Displacement damage occurs when a neutron imparts enough energy to displace an atom from its lattice position forming a vacancy. Neutrons can cause significant displacement damage to the atomic lattice and even cause fission reactions, if neutron absorption occurs. Indirect ionization can occur when a neutron collides with the atomic nuclei producing recoils, which then produce ionization along those recoil paths.

Conductivity can be described using the well know expression $\sigma=q \mu N$ where $q$ is electronic charge, $\mu$ is majority carrier mobility, and $\mathrm{N}$ is the majority carrier concentration. Since mobility is dependent upon the doping concentration and amount of displacement damage, it is expected that displacement damage will effectively decrease the mobility and the effective carrier concentration.

\section{TEST RESULTS}

Electrical specifications (datasheets) for these devices can be found at http://www.fairchildsemi.com/products. Electrical measurements of the different test parameters were performed under similar conditions specified in the datasheets of each tested device type (using commercial protocols).

\section{A. IGSS}

Figure 1 displays the averaged gate leakage current ( $\left.\mathrm{I}_{\mathrm{GSS}}\right)$ of the FSG, FSP, FS, and FR families of the devices tested. All measured values of $\mathrm{I}_{\mathrm{GSS}}$ currents were between 2.5 to 3.5 $\mathrm{nA}$ and none of the devices tested exhibited any notable change in $I_{G s s}$ even after a neutron exposure of $10^{15}$ neutron $\bullet \mathrm{cm}^{-2}$. The maximum allowable specification for $I_{G S S}$ is $100 \mathrm{nA}$.

\section{B. IDSS}

Figure 2 displays the measured drain leakage current of the FSG, FSP, FS and FR families of the devices tested when biased at $40 \%$ of the device's rated $B V_{D S S}$, which resulted in pre-radiation leakage currents between 2 to $4 \mathrm{nA}$. A significant increase was observed with increasing levels of neutron fluence. This effect is most likely caused by ionization as well as displacement damage. Figure 3 displays the measured drain leakage current when biased at $80 \%$ of the device's rated $B V_{D S S}$, which resulted in pre-radiation leakage currents between 3.5 to $6 \mathrm{nA}$. Again, a significant increase in leakage current was observed with increasing levels of neutron fluence.

\section{BVDSS}

As the silicon lattice is neutron irradiated, silicon atoms in the lattice are displaced. These reactions tend to decrease the effective doping of the bulk material and increase the resistivity of the silicon. A decrease in effective doping, in turn, increases the breakdown voltage. Figure 4 displays the drain breakdown voltage response when measured at drain current of $1 \mathrm{~mA}$ of the FSG, FSP, FS, and FP families of the devices tested. After neutron irradiation, a notable increase in the breakdown voltage was observed.

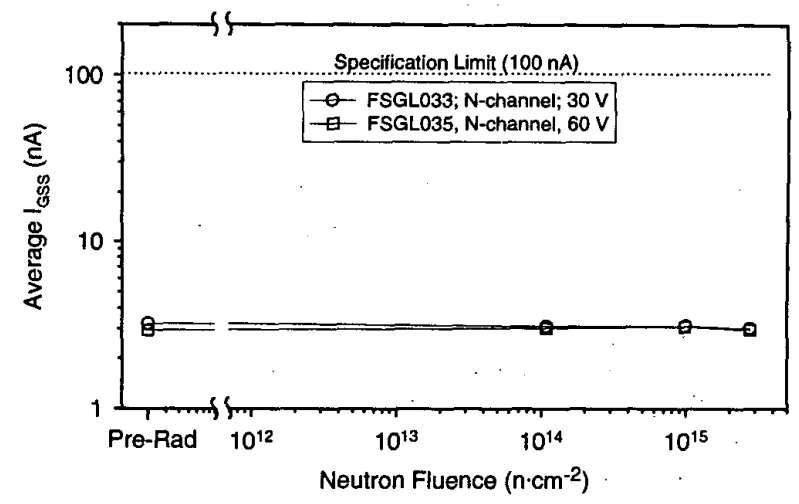

Fig. la. IGss response of the FSG family tested.

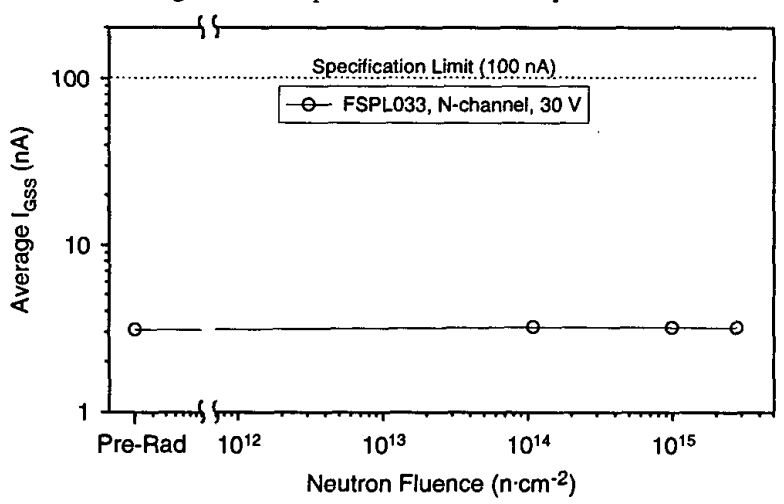

Fig. 1b. IGsS response of the FSP family tested.

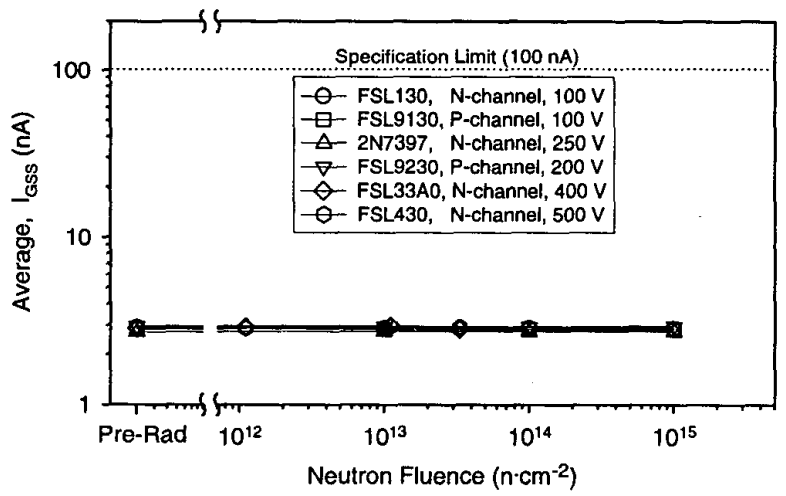

Fig. 1c. IGss response of the FS family tested.

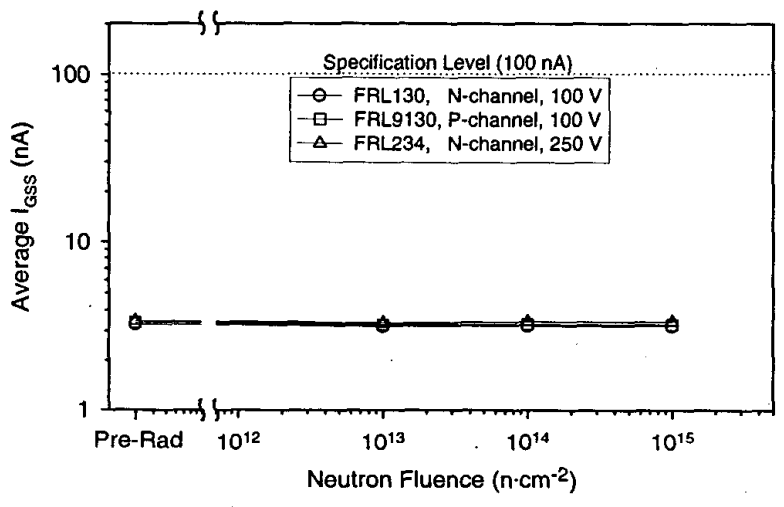

Fig. 1d. IGss response of the FR family tetsed

Fig. 1. Average gate leakage current (IGSS) of the devices tested from the FSG (1a), FSP (1b.), FS (1c.), and FR (1d.) families. 


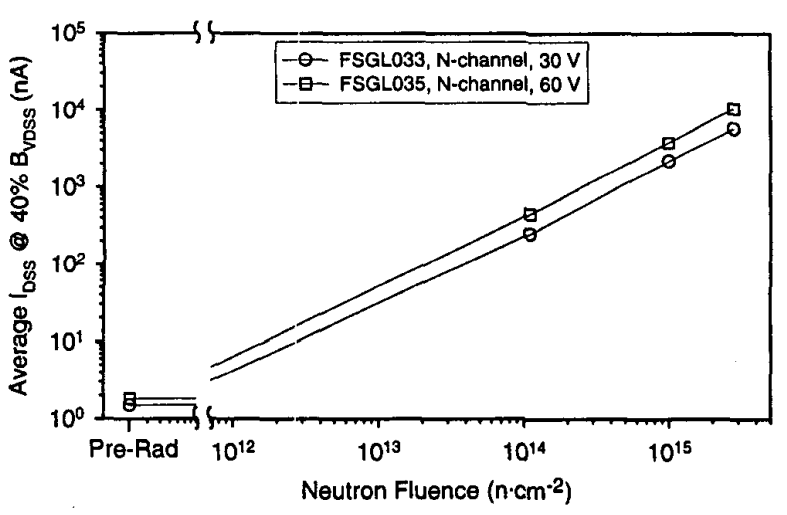

Fig. 2a. lDss response of the FSG family tested.

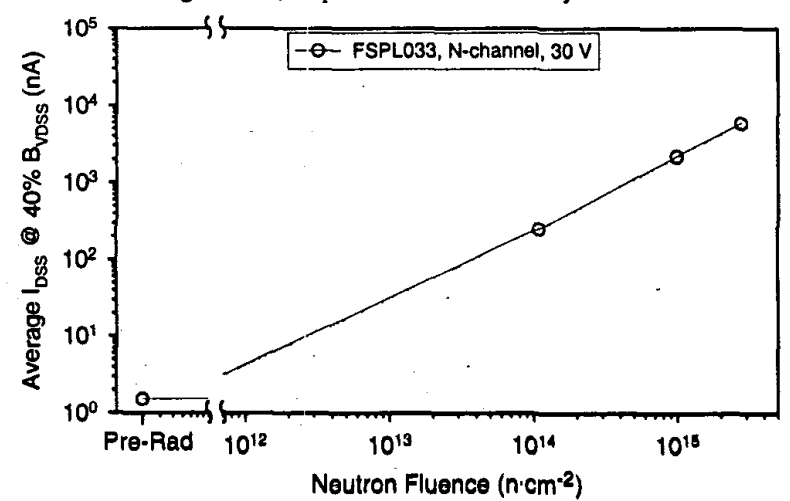

Fig. 2b. IDSs response of the FSP family tested.

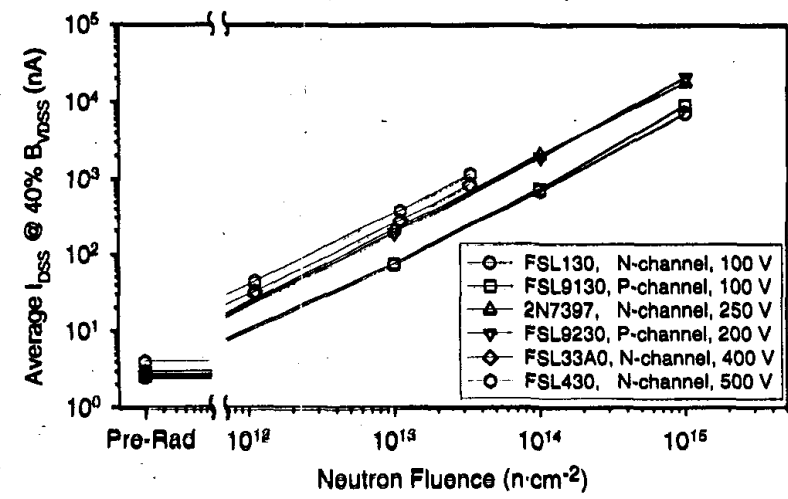

Fig. 2c. IDss response of the FS family tested.

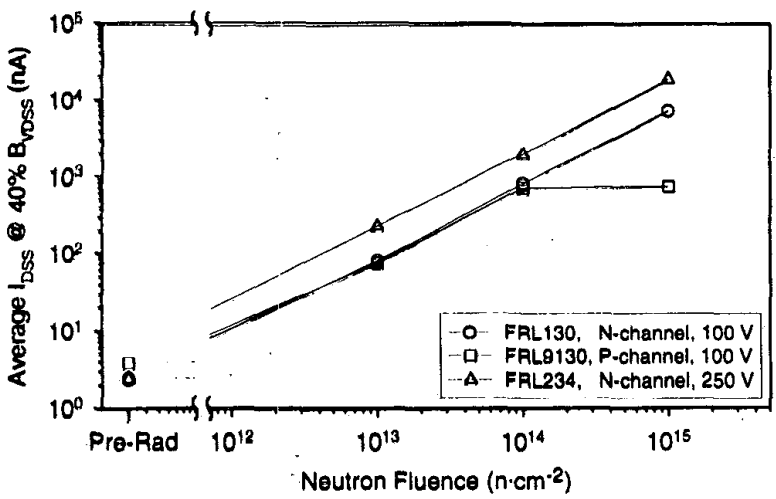

Fig. 2d. IDss response of the FR family tested.

Fig. 2. Average drain leakage current (loss) of the tested devices from the FSG (2a.), FSP (2b.), FS (2co.), FR (2d.) families at $40 \%$ of its rated BV DSs.

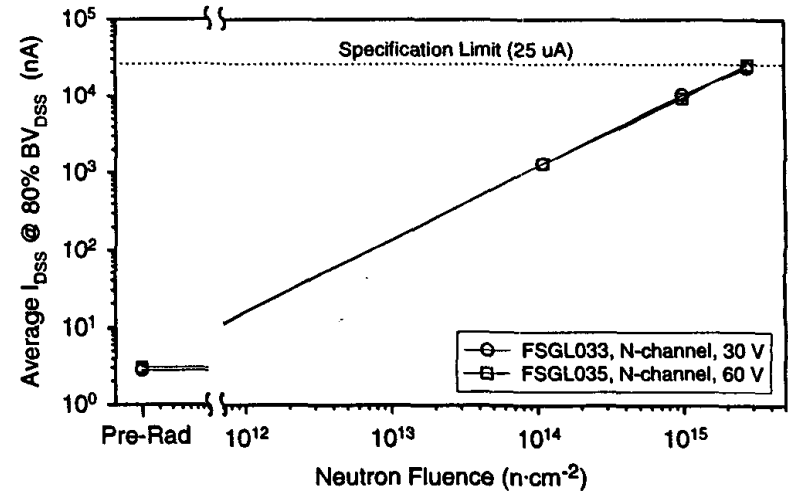

Fig. 3a. loss response of the FSG family tested.

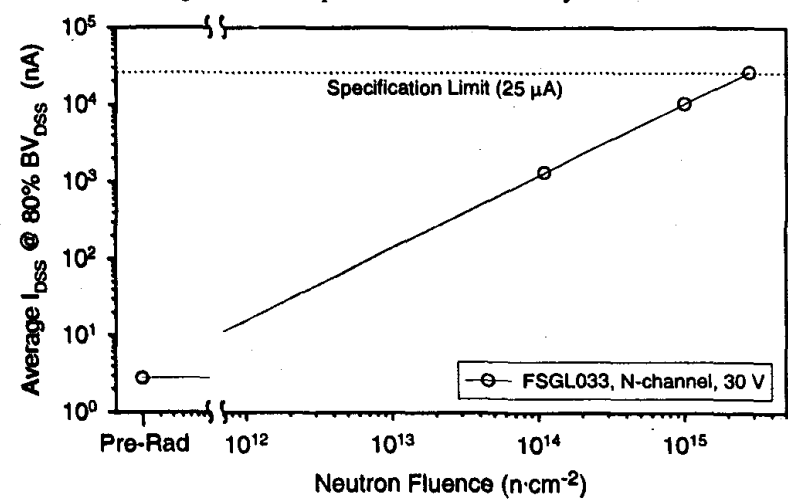

Fig. 3b. IDss response of the FSP family tested.

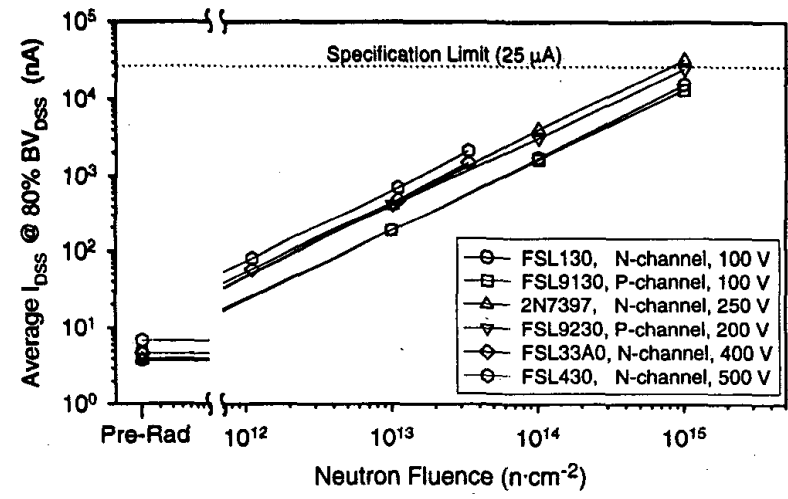

Fig. 3c. IDss response of the FS family tested.

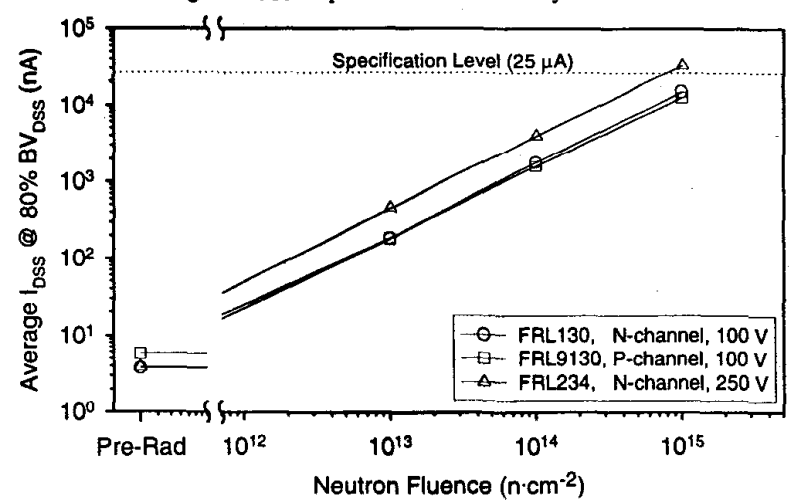

Fig. 3d. IDss response of the FR family tested.

Fig. 3. Average drain leakage current (lDss) of the tested devices from the FSG (3a.), FSP (3b.), FS (3c.), FR (3d.) families at $80 \%$ of its rated BV 


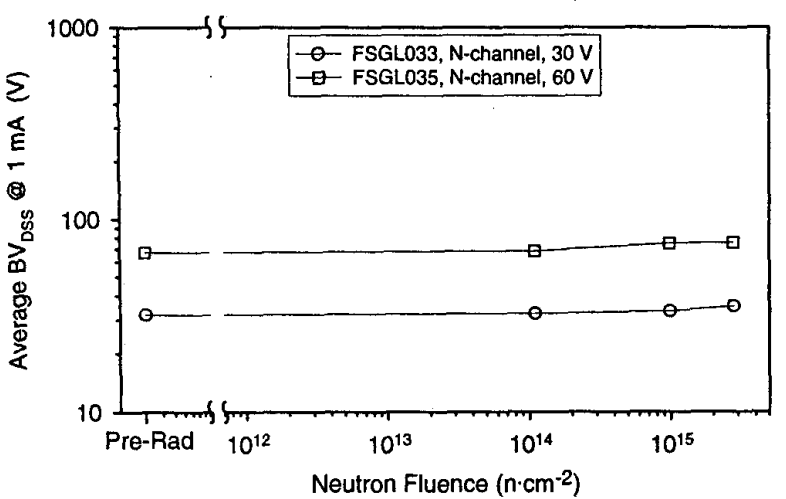

Fig. 4a. BVDss response of the FSG family tested.

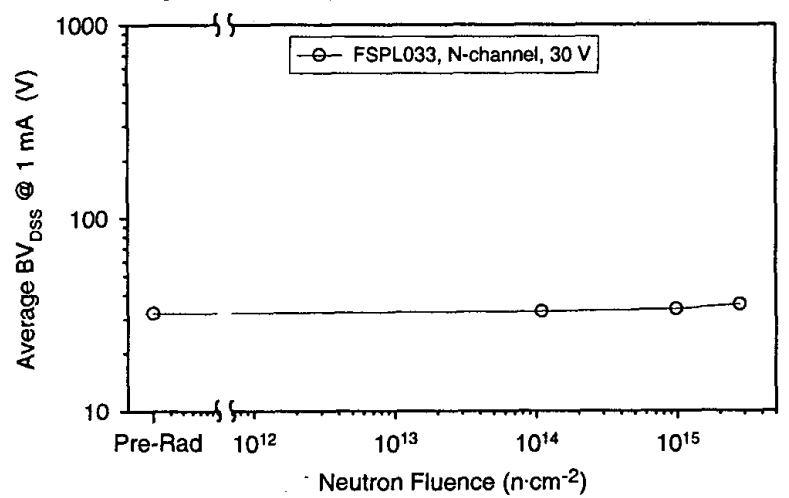

Fig. 4b. BV Dss response of the FSP family tested.

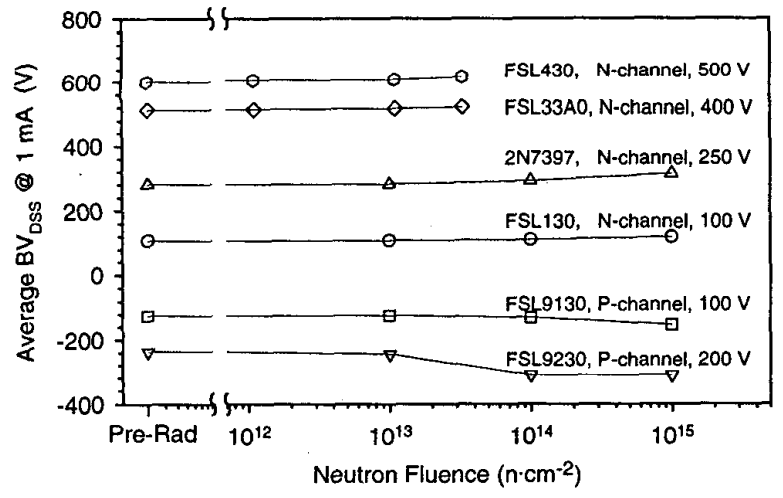

Fig. $4 \mathrm{c} . \mathrm{BV}_{\mathrm{DSs}}$ response of the FS family tested.

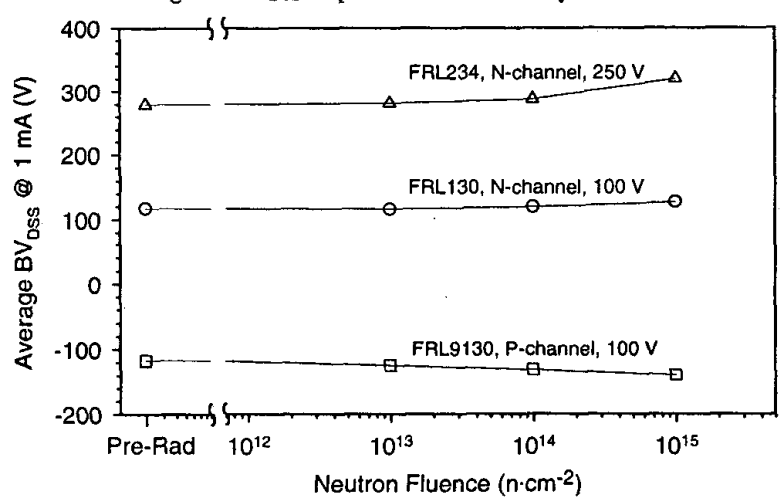

Fig. $4 \mathrm{~d}$. BV $\mathrm{V}_{\mathrm{DSs}}$ response of the FR family tested.

Fig. 4. Average drain breakdown voltage ( $\left.B V_{D S S}\right)$ of the tested devices from the FSG (4a.), FSP (4b.), FS (4c.), FR (4d.) families at IDS of $1 \mathrm{~mA}$.
D. VTH

Figure 5 displays the threshold voltage responses when measured at a drain current of $1 \mathrm{~mA}$ for $\mathrm{N}$-channel devices and at $-1 \mathrm{~mA}$ for P-channel devices. Figure 6 displays the threshold voltage responses when measured at a drain current of $5 \mathrm{~mA}$ for $\mathrm{N}$-channel devices and at $-5 \mathrm{~mA}$ for P-channel devices.

For both the $\mathrm{N}$ - and P-channel devices, the changes in threshold voltage are consistent with charge build-up in the gate oxide. It is most likely trapped holes induced by gamma radiation, which is incidental to contamination that is present when exposing devices to neutrons. Additional work is planned to separate the trapped charge $\left(\mathrm{N}_{\mathrm{OT}}\right)$ and interface states $\left(\mathrm{N}_{\mathrm{IT}}\right)$, but is not reported here.

\section{E. RDSON}

All $\mathrm{R}_{\mathrm{DSON}}$ measurements were taken using a gate bias of 10 and $12 \mathrm{~V}$ for the $\mathrm{N}$-channel devices and a gate bias of -10 and $-12 \mathrm{~V}$ for the $\mathrm{P}$-channel devices at different $\mathrm{I}_{D S}$ values. Figures 7 and 8 present the $R_{D S O N}$ responses of the FSGL033 and FSGL035 at $I_{D S}$ of 5, 10, and 15 A. Figure 9 presents the $R_{D S O N}$ response of the FSPL033 at $I_{D S}$ of 5, 10, and $15 \mathrm{~A}$. Figures $10-13$ present the $R_{D S O N}$ responses of the FSL13A0, 2N7397, FSL33A0, and FSL430 at $\mathrm{I}_{\mathrm{DS}}$ of 2, 3, and $5 \mathrm{~A}$. Figures 14 and 15 present the $R_{D S O N}$ responses of the FSL9130 and FSL923A0 at $I_{D S}$ of 2, 3, and 5 A. Figures 1618 present the $R_{D S O N}$ responses of the FRL130, FRL234, and FRL9130 at $\mathrm{I}_{\mathrm{DS}}$ of 2,3 , and $5 \mathrm{~A}$.

The on resistance is the electrical parameter, which was most likely to be influenced by displacement damage. Since the on-resistance is strongly dominated by the bulk resistance and this epitaxial layer will sustain a significant amount of displacement damage, the on-resistance is expected to increase significantly. An increase in on-resistance is expected because displacement damage decreases the mobility and effective doping, which, in turn, causes the onresistance to increase.

It has been known for many years that devices incorporating heavily doped, epitaxial layers (lowers the bulk resistivity) are less sensitive to neutron irradiation then those employing lightly doped epitaxial layers. Therefore, MOS devices with lower breakdowns, which use a heavily doped, epitaxial layer, have less degradation for a given neutron exposure in parameters such as $R_{D S O N}$ then devices with higher breakdown, which use a lightly doped epitaxial layer. This is graphically shown in Fig. 19. Changes in resistivity were explained by the work of Buehler [1] and later by Messenger and Ash [2].

\section{SUMMARY AND CONCLUSIONS}

The data collected in this investigation are in good agreement with the predicted behavior and previously recorded information on neutron irradiation of vertical MOSFET devices. This study was undertaken to revalidate the performance of several radiation-hardened power MOSFET families produced by Fairchild Semiconductor [4], [7]. These data can be used to predict the electrical performance of these devices and similar devices when irradiated to neutrons. 


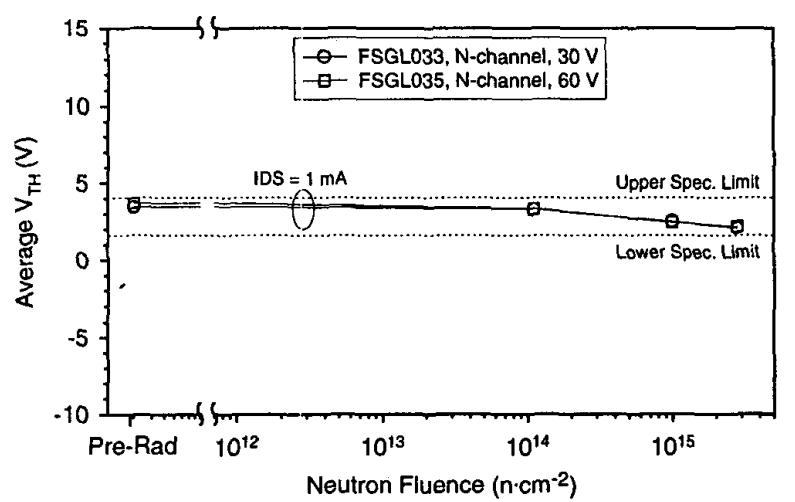

Fig. 5a. $V_{T H}$ response of tested devices from the FSG family.

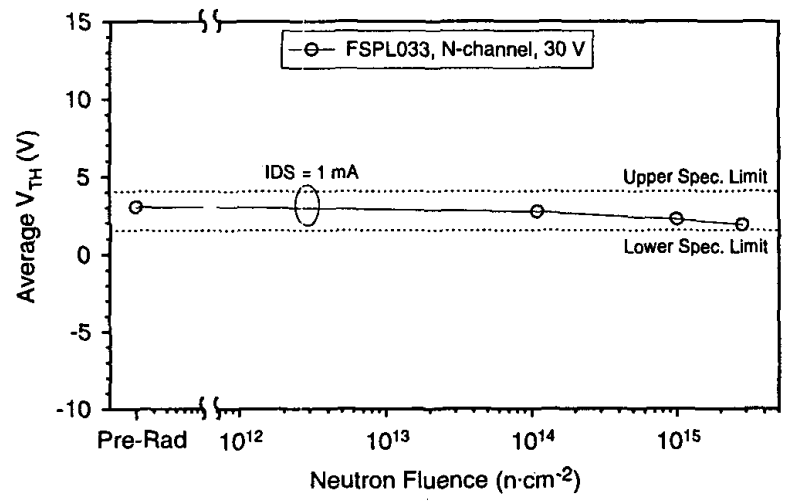

Fig. $5 b$. $V_{T H}$ response of tested devices from the FSP family.

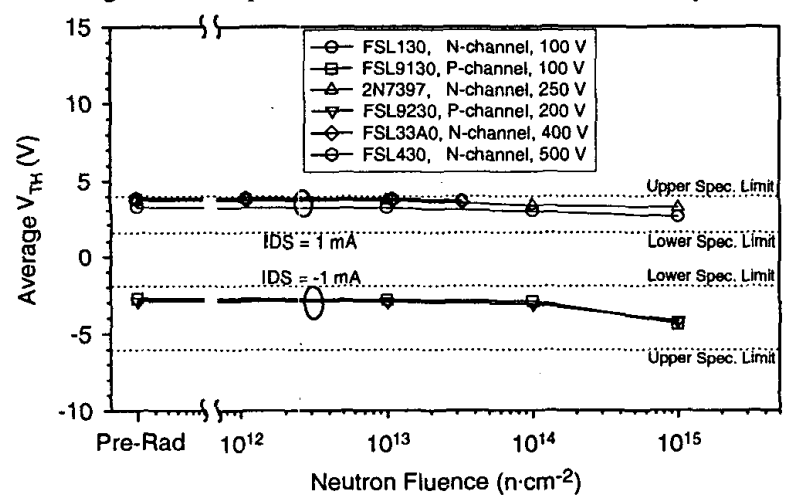

Fig. 5c. $V_{\mathrm{TH}}$ response of tested devices from the FS family.

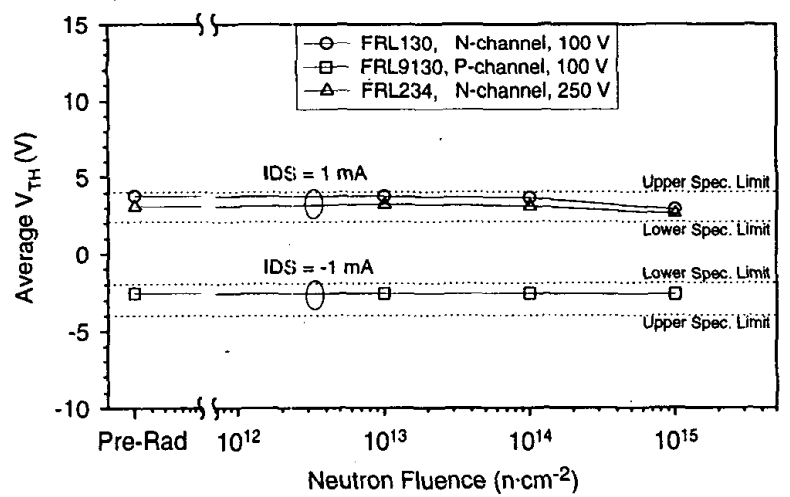

Fig. 5d. $V_{T H}$ resporise of tested devices from the FR family

Fig. 5. Average threshold voltage $\left(\mathrm{V}_{\mathrm{TH}}\right)$ of the tested devices from the FSC (5a.), FSP (5b.), FS (5c.), FR (5d.) families at IDS of $1 \mathrm{~mA}$.

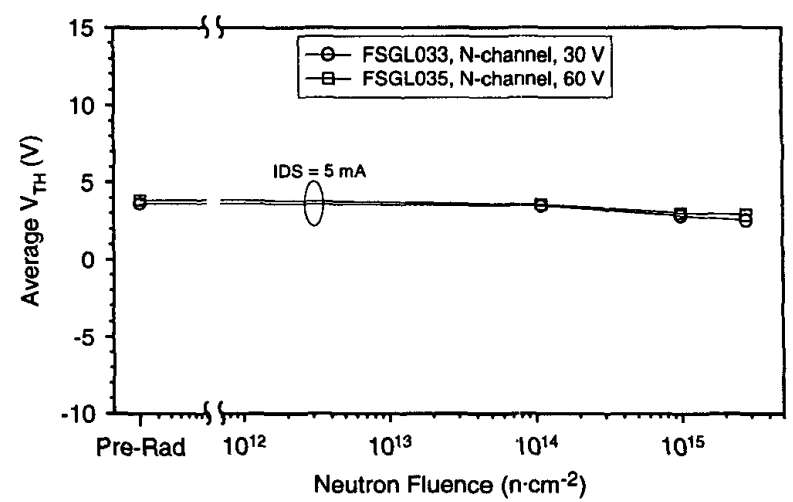

Fig. 6a. $V_{T H}$ response of tested devices from the FSG family.

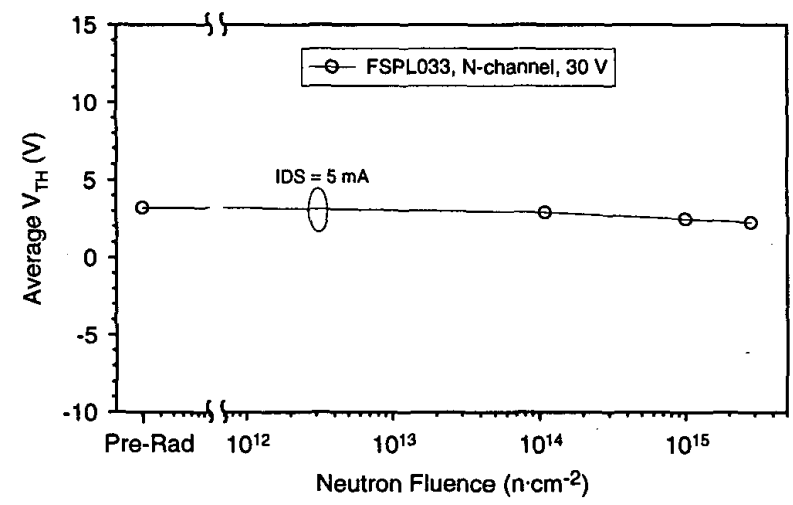

Fig. $6 \mathrm{~b}$. $\mathrm{V}_{\mathrm{TH}}$ response of tested devices from the FSP family.

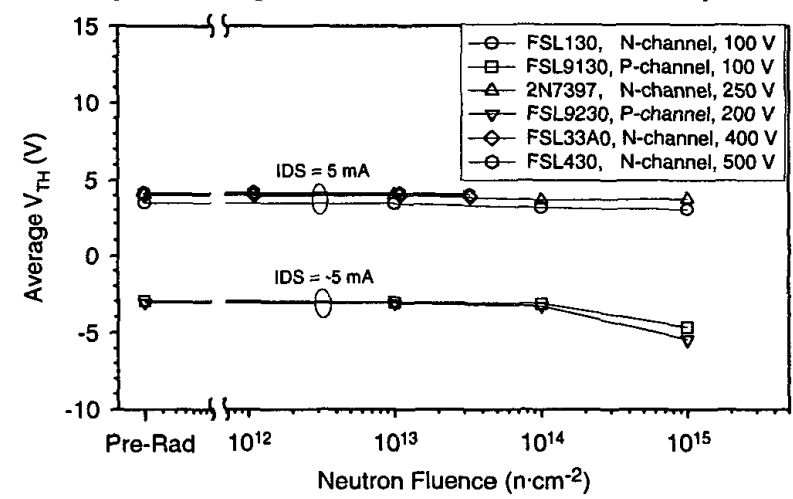

Fig. 6c. $V_{\text {TH }}$ response of tested devices from the FS family.

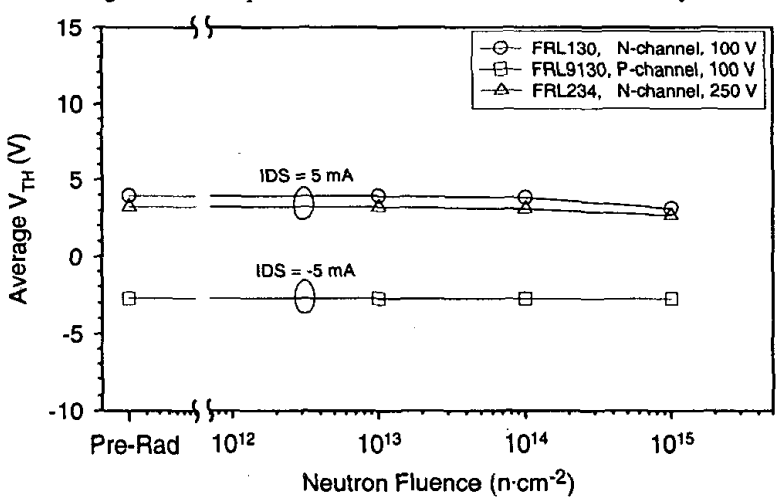

Fig. 6d. $V_{T H}$ response of tested devices from the FS family.

Fig. 6. Average threshold voltage $\left(\mathrm{V}_{\mathrm{TH}}\right)$ of the tested devices from the FSG (6a.), FSP (6b.), FS (6c.), FR (6d.) families at IDS of $5 \mathrm{~mA}$. 


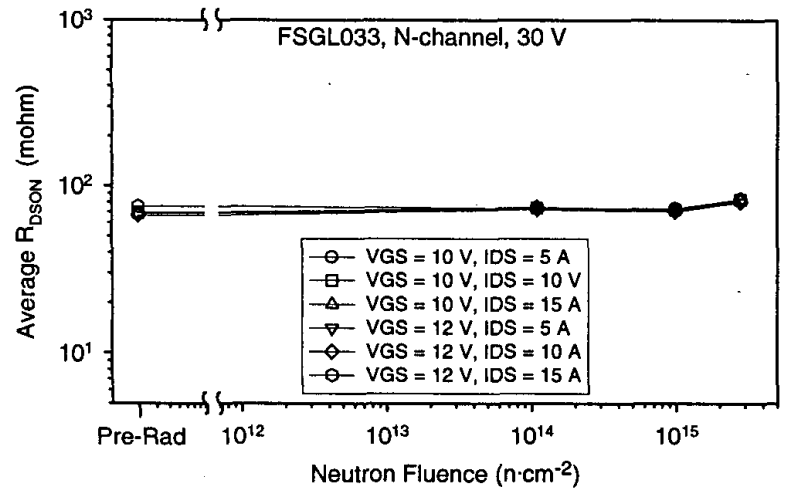

Fig. 7. Rpson responses of the FSGL033.

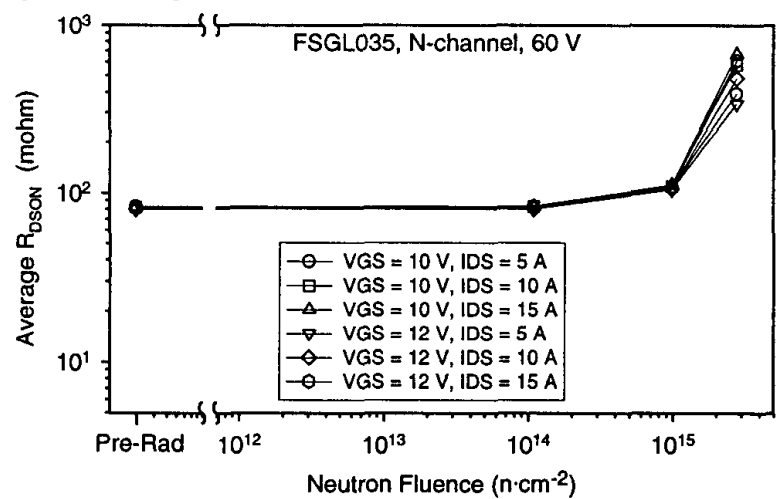

Fig. 8. RDson responses of the FSGL035 (bottom).

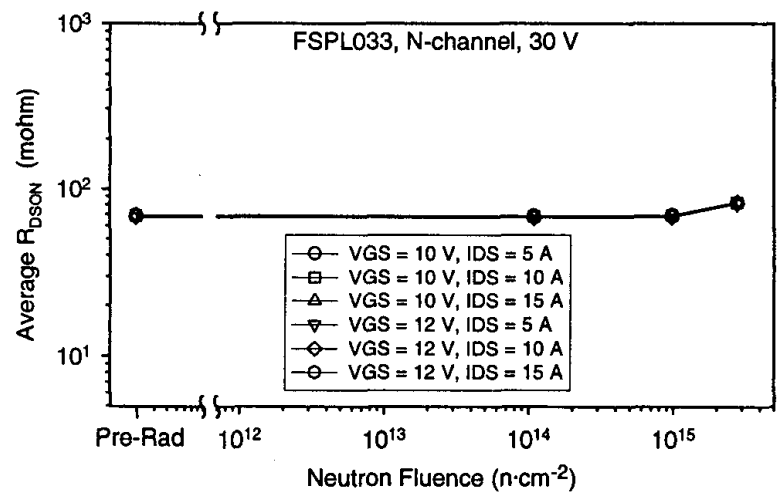

Fig. 9. RDSON responses of the FSPL033.

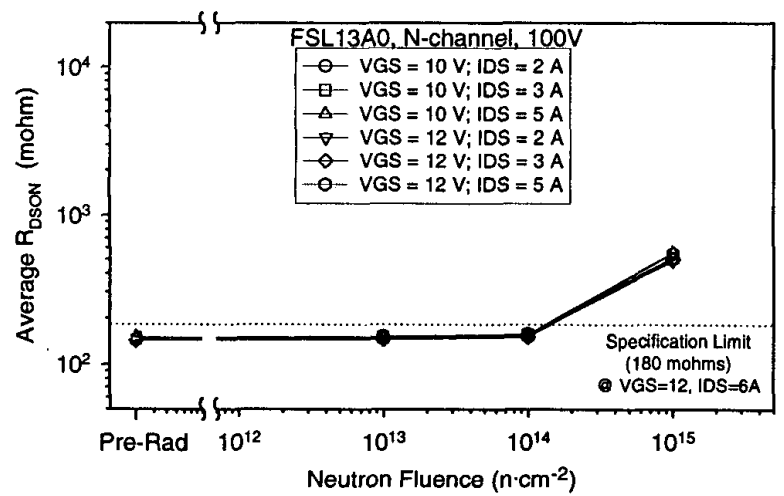

Fig. 10. RDson responses of the FSL13A0.

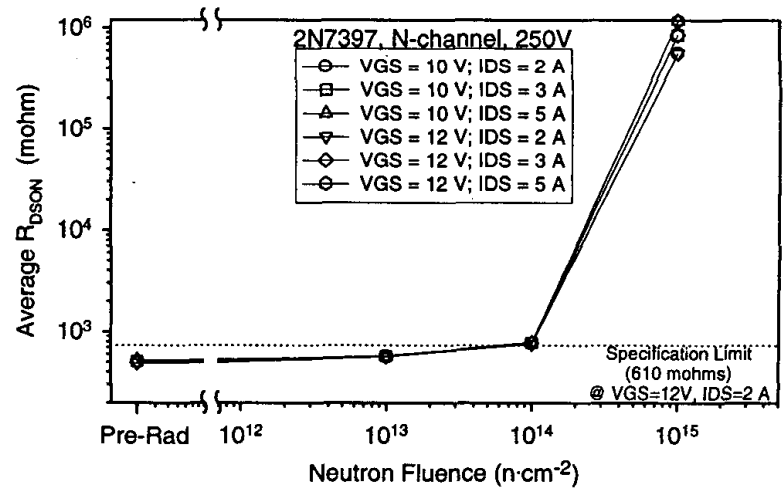

Fig. 11. $R_{\text {DsoN }}$ responses of the 2 N7397.

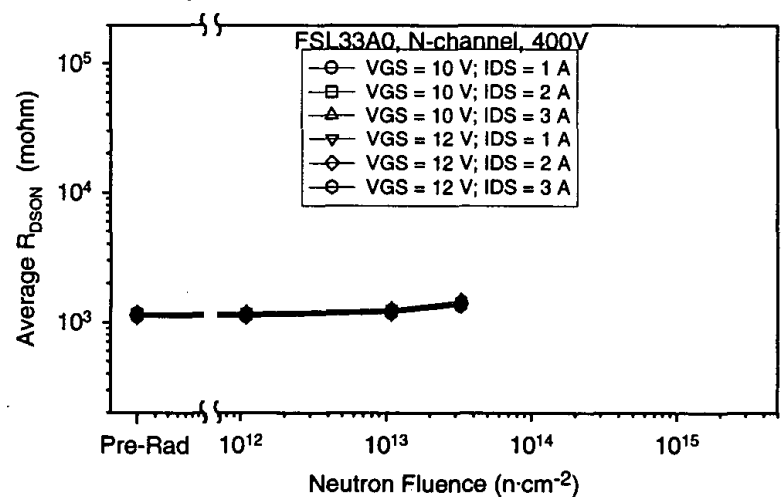

Fig. 12. $\mathrm{R}_{\mathrm{DSON}}$ responses of the FSL33A0.

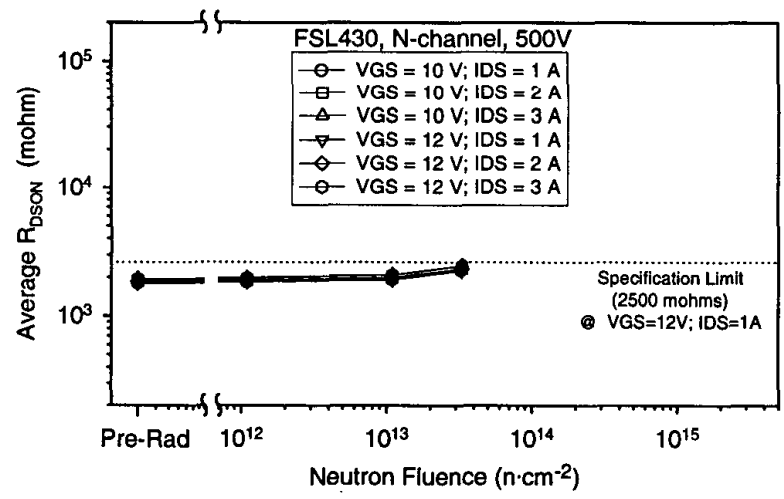

Fig. 13. RDson responses of the FSL430.

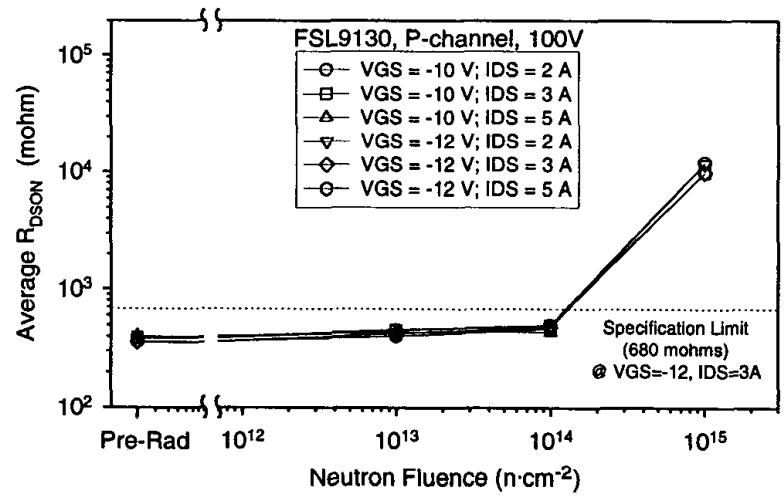

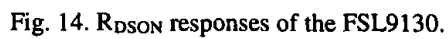




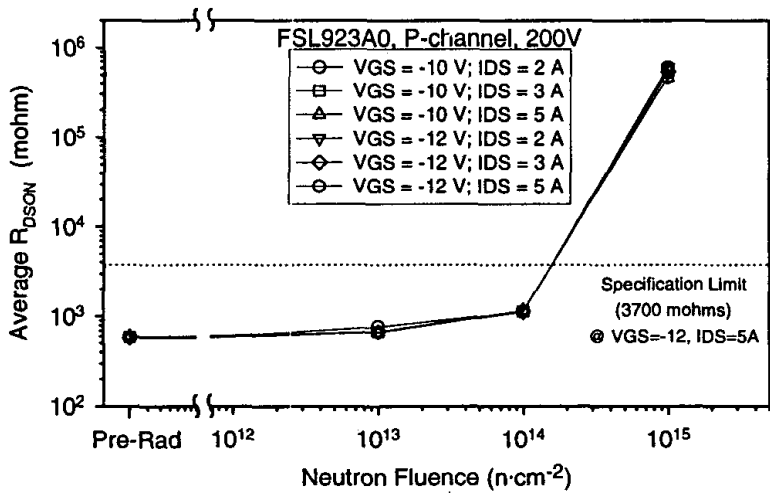

Fig. 15. RDson responses of the FSL923A0.

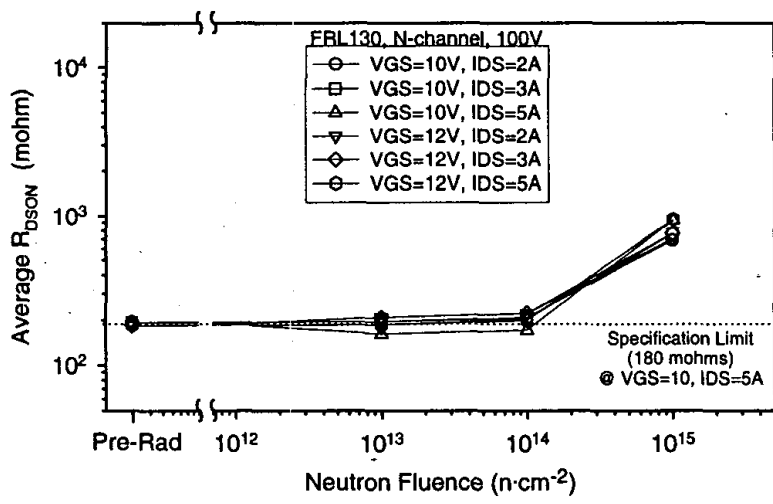

Fig. 16. RDSON responses of the FRL130.

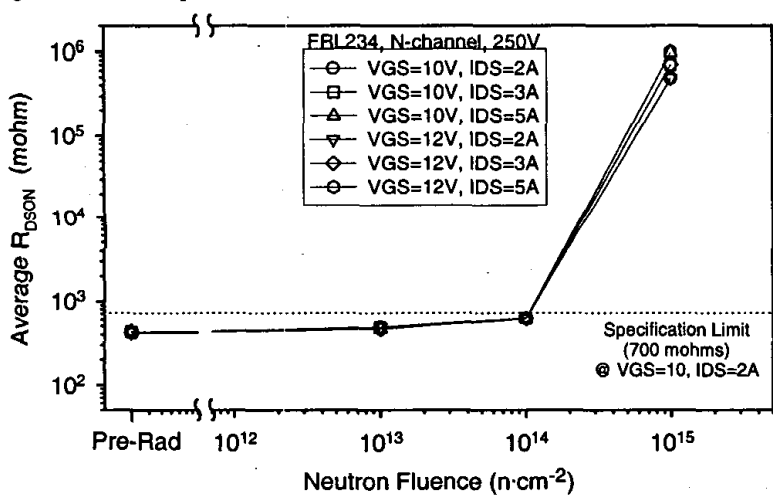

Fig. 17. RDson responses of the FRL234.

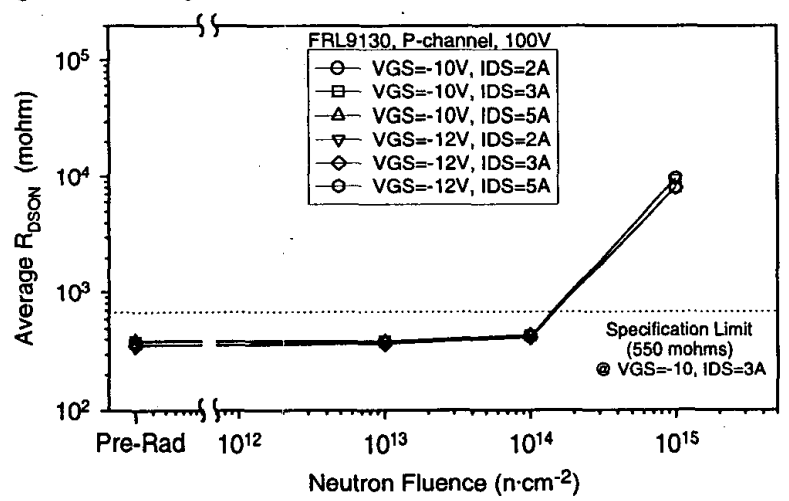

Fig. 18. RDSon responses of the FRL9130.

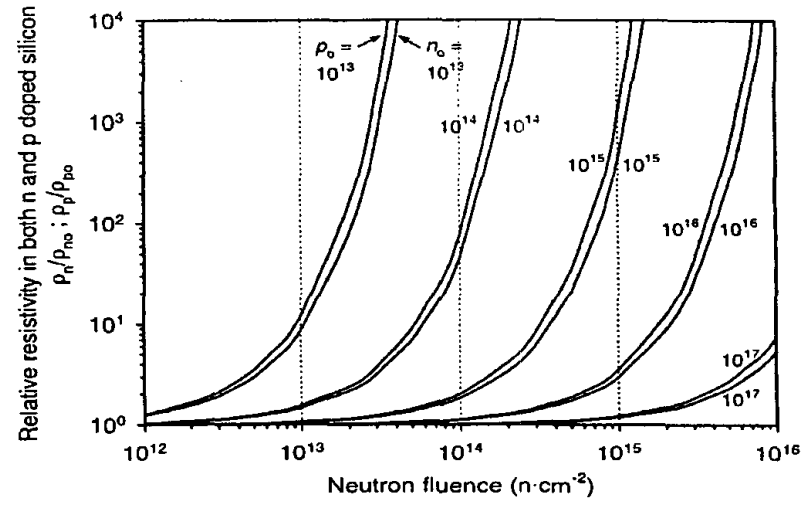

Fig. 19. Relative resistivity of doped silicon [1] and [2].

Key to this revalidation was the establishment that the products performed in excess of their specifications based upon the manufacturers datasheets. Additional products are presently scheduled to undergo irradiation, extending the information to include additional device types from these radiation-hardened families. These data will be included in subsequent reports.

\section{ACKNOWLEDGMENT}

The authors give special thanks to Fairchild Semiconductor for their program support and the Pennsylvania State University Breazeale TRIGA Mark III nuclear reactor personnel for providing neutron facilities.

\section{REFERENCES}

[1.] M. G. Buehler, "Design Curves for Predicting Fast Neutron-Induced Resistivity Changes in Silicon,"Proc. IEEE 56, 1741 (1968).

[2.] G. C. Messenger and M. S. Ash, "The Effects of Radiation on Electronic Systems," Von Nostrand Reinhold Company, New York, 1986, p. 200.

[3.] D. L. Blackburn, T. C. Robbins, and K. F. Galloway, "VDMOS Power Transistor Drain-Source Resistance Radiation Dependency," IEEE TNS, Vol. NS-28, No. 6, Dec. 1981, p. 4354-4359.

[4.] C. F. Wheatley; "Radiation Hardening of Vertical DMOS (VDMOS) Power MOSFETs;" Harris Semiconductor Sector, Application Note AN-8831, Dec. 1988.

[5.] H. Volmerange \& A. A. Witteles; "Radiation Effects on MOS Power Transistors;" IEEE TNS, Vol. 29, Dec. 1982, p. 1565-1568.

[6.] G. B. Roper \& R. Lowis; "Development of a Radiation Hard NChannel Power MOSFET;" IEEE TNS, Vol. 30, Dec. 1983, p. 41104115.

[7.] C. F. Wheatley \& L. S. Jamiolkowski; "Development of Radiation Hardened Power MOSFETs;" Final Report, Contract \# N00164-86-C0182, Prepared for NAVSEA-Crane, 30 Sep 90. 